\title{
Methylation and expression of mismatch repair gene human mutS homolog 2 in myelodysplastic syndromes
}

\author{
XIAOLIU LIU ${ }^{1}$, SUFANG LIU ${ }^{2}$, JIAN LEI $^{3}$, LIXIN ZOU ${ }^{1}$, LE XIAO $^{2}$ and GUANGSEN ZHANG ${ }^{2}$ \\ ${ }^{1}$ Department of Hematology, The Affiliated Changsha Hospital, Hunan Normal University, Changsha, Hunan 410006; \\ ${ }^{2}$ Division of Hematology, Institute of Molecular Hematology, The Second Xiang-Ya Hospital, Central South University, \\ Changsha, Hunan 410011; ${ }^{3}$ Department of Pathology, The Affiliated Tumor Hospital, Xiangya School of Medicine, \\ Central South University, Changsha, Hunan 410013, P.R. China
}

Received September 20, 2016; Accepted October 26, 2017

DOI: $10.3892 /$ etm.2017.5402

\begin{abstract}
As a highly heterogeneous disease, the pathogenesis of myelodysplastic syndrome (MDS) has not been well defined. In the present study, human mutS homolog 2 (hMSH2) promoter methylation was detected with methylation-specific polymerase chain reaction (PCR). The function of hMSH2 was analyzed by microsatellite instability (MSI) detection of BAT-26, and hMSH2 expression was evaluated using reverse transcription-quantitative PCR in 60 patients with MDS. The results revealed methylation of the hMSH2 promoter in 18 patients with MDS who have an overall prevalence of $30 \%$ (95\% confidence interval, 18.4-41.6\%). Among the patients with hMSH2 methylation, 2 patients exhibited MSI. It was demonstrated that hMSH2 promoter methylation was increased in MDS with an increase in Revised International Prognostic Scoring System (IPSS-R) risk, and patients with higher hMSH2 promoter methylation had shorter overall survival by Kaplan-Meier analysis $(\mathrm{P}=0.011)$. In addition, it was also observed that decreased hMSH2 mRNA expression was associated with high IPSS-R risk group (high/very high vs. intermediate, $\mathrm{P}=0.003$ ), and $\mathrm{hMSH} 2 \mathrm{mRNA}$ expression in CD34 positive bone marrow cells was lower compared with that in CD34 negative cells of patients with $\mathrm{MDS}(\mathrm{P}=0.029)$. Methylation of hMSH2 may be valuable for prognostic evaluation and progression prediction of MDS. Furthermore, hMSH2 may serve a key function in the pathogenesis and prognosis of MDS.
\end{abstract}

Correspondence to: Dr Guangsen Zhang, Division of Hematology, Institute of Molecular Hematology, The Second Xiang-Ya Hospital, Central South University, 139 Renmin Road, Changsha, Hunan 410011, P.R. China

E-mail: zgsllzy@163.com

Key words: human mutS homolog 2, methylation, microsatellite instability, myelodysplastic syndromes, prognosis

\section{Introduction}

Myelodysplastic syndrome (MDS) is a group of heterogeneous cloned disorders of hematologic malignancies characterized by ineffective hematopoiesis and risk of progression to acute myeloid leukemia (AML) (1). According to the 2008 World Health Organization (WHO) classification system for hematologic cancers, primary MDS is one of five major categories of myeloid neoplasms (2). As a highly heterogeneous disease, the pathogenesis of MDS has not well been defined. Associated molecular mechanisms include chromosomal abnormalities, gene mutations, epigenetic changes and gene expression abnormalities (3).

In the process of tumorigenesis, in addition to genetic alterations such as gene mutations and chromosomal instability, epigenetic dysregulation may also result in tumor suppressor gene silencing and loss-of-function (4). DNA methylation is an important mechanism of epigenetic regulation. As with other tumors, MDS development is a complex, multi-staged process that is controlled by many factors. Besides genetic abnormalities, gene methylation is highly correlated with MDS (5,6). Cytosine methylation status may influence gene transcription, contributing to the growth and differentiation of MDS clones. Unlike genetic abnormalities, DNA methylation is a reversible process, which provides a basis for MDS treatment research (7).

Mismatch repair (MMR) genes are a group of highly conserved housekeeping genes in humans. The function of the encoded proteins is to repair DNA base mismatches, enhancing the fidelity of DNA replication and maintaining genomic stability $(8,9)$. Human mutS homolog 2 (hMSH2) is an MMR that serves a key role in the repair of DNA damage (10). Dysfunction of hMSH2 may lead to errors in DNA replication, formation of the malignant clone and tumorigenesis (11).

The aims of the present study were to determine the status of hMSH2 gene promoter methylation and microsatellite instability (MSI), and to evaluate the significance of hMSH2 gene methylation and expression for the pathogenesis and prognostic assessment of patients with MDS, according to the Revised International Prognostic Scoring System (IPSS-R) for assessing risk (12). 


\section{Patients and methods}

Patients. A total of 60 patients with MDS (median age, 58.5 years; age range, 23-80 years; male, $n=36$; female, $\mathrm{n}=24$ ) were recruited into the study from the Division of Hematology, The Second Xiang-Ya Hospital, Central South University, (Changsha, China) between March 2011 and March 2013. In addition to collecting their medical history, the bone marrow cell morphology, bone marrow biopsy, conventional cytogenetic analysis and chromosome fluorescence in situ hybridization (FISH) were performed. MDS was diagnosed according to the WHO 2008 criteria (2). The risk-stratification of MDS was performed following IPSS-R standard (12). A total of 15 subjects with normal hemograms (median age, 52 years; age range, 22-70 years; male, $n=8$; female, $n=7$ ) were recruited from the Division of Hematology, The Second Xiang-Ya Hospital, Central South University between March 2011 and March 2013 and used as controls. Bone marrow samples from patients with MDS and control individuals were obtained following provision of written informed consent. The present study was approved by the institutional ethics committees of The Second Xiang-Ya Hospital, Central South University (Changsha, China), and the procedures were conducted strictly in accordance with the Declaration of Helsinki.

Conventional cytogenetics analysis. Giemsa-banding for karyotyping was performed on heparinized bone marrow samples as previously reported (13). Bone marrow cells were cultured at $37^{\circ} \mathrm{C}$ in a humidified atmosphere containing $5 \% \mathrm{CO}_{2}$ using standard culture techniques. A hypotonic solution $[0.05 \mu \mathrm{g} / \mathrm{ml}$ colchicine (cat. no. C9754; Sigma-Aldrich; Merck KGaA, Darmstadt, Germany)] was added to the cells and they were centrifuged at $400 \mathrm{x} \mathrm{g}$ for $5 \mathrm{~min}$ at $18-20^{\circ} \mathrm{C}$. Following the addition of a fixative (ratio of methanol and glacial acetic acid, $3: 1$ ) for $3-5 \mathrm{~min}$ at $18-20^{\circ} \mathrm{C}$ and trypsin treatment, Giemsa staining was performed for 5-10 min at $37^{\circ} \mathrm{C}$. The cells were then observed using a fluorescence microscope (Olympus BX51; Olympus Corporation, Tokyo, Japan). A total of 20 metaphase cells for each patient with available samples were karyotyped according to the International System for Human Cytogenetic Nomenclature criteria (14).

FISH analysis. FISH was performed as previously described (15). Interphase FISH test to $\operatorname{detect} \operatorname{del}(5 \mathrm{q}) /-5$, $\operatorname{del}(7 \mathrm{q}) /-7$, trisomy 8 , $\operatorname{del}(20 q)$ on bone marrow mononuclear cells (BMNCs) when the bone marrow examinations were performed according to the manufacturer's protocol. The probes used were the Vysis LSI EGR1/D5S23, D5S721 Dual Color Probe kit (CE) (cat. no. 08L68-020), Vysis LSI D7S522 SpectrumOrange/Vysis CEP 7SpectrumGreen Probes (ASR; cat. no. 05J85-001), Vysis CEP 8 SpectrumOrange Direct Labeled Fluorescent DNA Probe kit (CE; cat. no. 07J22-008) and Vysis D20S108 FISH Probe kit (CE; cat. no. 05N02-020; all Abbott Laboratories, Abbott Park, IL, USA). For each sample $\geq 200$ cells were reviewed.

Cell isolation. BMNCs were isolated from fresh bone marrow samples by Ficoll-Paque (Tianjin Haoyang Biological Products Technology Co., Ltd., Tianjin, China) density centrifugation at
$400 \mathrm{x} \mathrm{g}$ for $10 \mathrm{~min}$ at $18-20^{\circ} \mathrm{C}$ ). To enrich cluster of differentiation 34 positive (CD34+) cells, BMNCs were separated using an EasySep Human CD34 Positive Selection kit (Stemcell Technologies, Inc., Vancouver, BC, Canada). The CD34 negative (CD34-) cells were also collected simultaneously. Then, the genomic DNA and total RNA were extracted, and stored in a freezer at $-80^{\circ} \mathrm{C}$.

Methylation-specific polymerase chain reaction (PCR). Genomic DNA was extracted from BMNCs (CD34+ and CD34-) using a Genomic DNA kit (Tiangen Biotech Co., Ltd., Beijing, China). Methylation-specific PCR for evaluating the methylation status of gene promoters was performed as previously described (16). Bisulfite conversion of DNA was performed using the EZ DNA Methylation-Gold kit (Zymo Research Corporation, Irvine, CA, USA). The primers for the methylation assay were as previously described (17). Reactions were carried out in a total volume of $20 \mu 1$, containing $1 \mu \mathrm{l}$ bisulfite-modified DNA, $2 \mu \mathrm{l}$ 10X PCR buffer, $1.6 \mu \mathrm{ldNTP}$ mixture $(2.5 \mathrm{mM}$ each), $0.5 \mu \mathrm{l}$ forward primer $(20 \mu \mathrm{M}), 0.5 \mu \mathrm{l}$ reverse primer $(20 \mu \mathrm{M}), 0.1 \mu \mathrm{l}$ Taq Hot Start Polymerase (5 U/ $\mu$; Tiangen Biotech Co., Ltd.) and $14.3 \mu \mathrm{l}$ distilled $(\mathrm{d}) \mathrm{H}_{2} \mathrm{O}$. Reaction mixtures were denatured at $95^{\circ} \mathrm{C}$ for $2 \mathrm{~min}$, then amplification was performed for 35 cycles $\left(95^{\circ} \mathrm{C}\right.$ for $30 \mathrm{sec}, 60^{\circ} \mathrm{C}$ for $30 \mathrm{sec}$ and $72^{\circ} \mathrm{C}$ for $40 \mathrm{sec}$ ), followed by a final extension at $72^{\circ} \mathrm{C}$ for $5 \mathrm{~min}$. DNA from control subjects was used as a negative control. DNA from leukocytes of a healthy individual treated with SssI methyltransferase (New England BioLabs, Inc., Ipswich, MA, USA) was used as a positive control for methylated alleles. Results from duplicate experiments were used to determine methylation status.

MSI detection. BAT-26 microsatellite marker was amplified by PCR from genomic DNA extracted from BMNCs of the controls and patients with MDS using previously described primers (18): Forward, 5'-TGACTACTTTTGACTTCA GCC-3' and reverse, 5'-AACCATTCAACATTTTTAACC C-3'. The reactions were carried out in a total volume of $10 \mu \mathrm{l}$, which contained $2 \mu \mathrm{l}$ DNA, $5 \mu 1$ 2X PCR Master mix (Tiangen Biotech Co., Ltd.), $0.5 \mu$ l forward primer $(10 \mu \mathrm{M})$, $0.5 \mu \mathrm{l}$ reverse primers $(10 \mu \mathrm{M})$ and $2 \mu \mathrm{l} \mathrm{dH}_{2} \mathrm{O}$. Reaction mixtures were denatured at $95^{\circ} \mathrm{C}$ for $5 \mathrm{~min}$, then amplification was performed for 35 cycles $\left(95^{\circ} \mathrm{C}\right.$ for $30 \mathrm{sec}, 55^{\circ} \mathrm{C}$ for $30 \mathrm{sec}$ and $72^{\circ} \mathrm{C}$ for $30 \mathrm{sec}$ ), followed by a final extension of $72^{\circ} \mathrm{C}$ for $5 \mathrm{~min}$. Products were subjected to $10 \%$ SDS-PAGE, and the gels were silver-stained as follows: Oxidized by $1 \%$ nitric acid for $5 \mathrm{~min}$, silver stained by $0.2 \%$ silver nitrate (containing $150 \mu \mathrm{l} / 100 \mathrm{ml}$ formaldehyde) for $2 \mathrm{~min}$, then developed by $3 \%$ sodium carbonate (containing $75 \mu \mathrm{l} / 100 \mathrm{ml}$ formaldehyde).

Reverse transcription-quantitative PCR (RT-qPCR) analysis. Total RNA from BMNCs was extracted using TRIzol reagent (Invitrogen; Thermo Fisher Scientific, Inc., Waltham, MA, USA). An equal amount ( $3 \mu \mathrm{g})$ of total RNA was used for cDNA synthesis with the MMLV Reverse Transcription kit (Invitrogen; Thermo Fisher Scientific, Inc.) according to the manufacturer's protocol. The cDNA was amplified and quantified using SYBR Green qPCR kit (Invitrogen; Thermo Fisher 
Scientific, Inc.). Primer sequences were as follows: hMSH2 forward, 5'-AGAAGCCCAGGATGCCATTG-3' and reverse, 5'-GGAACAGGTGCTCCATTTGAC-3'; GAPDH forward, 5'-ATGGGGAAGGTGAAGGTCG-3' and reverse, 5'-GGG TCATTGATGGCA ACAATATC-3'. Transcribed cDNA was amplified and quantified by a fluorescent qPCR using a THUNDERBIRD ${ }^{\circledast}$ SYBR $^{\circledR}$ qPCR mix (Toyobo Life Science, Osaka, Japan). To test the specificity of the PCR reaction, products were subjected to melting curve analysis and conventional $2 \%$ agarose gel electrophoresis ( $5 \mu 1 /$ lane) to rule out the synthesis of unspecific products. All quantitative assays were performed in duplicate. Values obtained for the target gene expression were normalized to GAPDH and calculated using the double-standard curves method (19).

Statistical analysis. Statistical analyses were performed using SPSS 13.0 software (SPSS, Inc., Chicago, IL, USA). All P-values were two-tailed and $\mathrm{P}<0.05$ was considered to indicate a statistically significant difference. The prevalence of hMSH2 methylation was estimated with the $95 \%$ confidence interval (CI). Continuous variables were reported as medians and interquartile ranges and compared using the Wilcoxon signed-rank test. Categorical variables were reported as count and percentage and compared using the Chi-squared test. Survival curves were constructed using the Kaplan-Meier method, using the interval from the date of diagnosis to the date of last contact or mortality, and compared using the log-rank test.

\section{Results}

hMSH2 methylation and clinical associations. hMSH2 methylation was analyzed in 60 patients with MDS. The age of patients at diagnosis ranged from 23 to 80 years (median, 58.5 years). The ratio of male:female was $1.5: 1$. According to WHO criteria, patients were classified as refractory anemia (RA; $n=9)$, RA with ringed sideroblasts $(n=2)$, refractory cytopenia with multilineage dysplasia (RCMD; $n=18)$, RA with excess blasts-1 (RAEB-1; n=9), RA with excess blasts-2 (RAEB-2; n=12), MDS-unclassifiable (MDS-U; n=6) and AML with myelodysplasia-related changes (AML-MRC; $n=4$ ). According to IPSS-R standards, patients were classified into very low $(n=1)$, low $(n=15)$, intermediate $(n=21)$, high $(n=16)$ and very high $(\mathrm{n}=7)$ risk groups (Table $\mathrm{I})$.

Methylation of the hMSH2 promoter was identified in 18 of 60 patients with MDS. Overall prevalence was $30 \%$ (95\% CI, 18.4-41.6\%). None of the 15 controls exhibited hMSH2 methylation (Fig. 1). In the BMNCs obtained from MDS, $11.1 \%$ of RA/RCMD, $57.1 \%$ of RAEB-1/RAEB-2 and $50.0 \%$ of AML-MRC exhibited hMSH2 gene methylation. The prevalence of hMSH2 methylation was 10.8 and $60.9 \%$ in very low/low/intermediate and high/very high IPSS-R risk groups, respectively. Therefore, hMSH2 methylation was associated with higher risk patients $(\mathrm{P}<0.001$, Table I).

To investigate whether hMSH2 methylation was associated with clinical phenotypes and hematologic profiles, parameters were compared in patients with or without hMSH2 methylation. The results indicated that patients with more bone marrow blast cells had a higher rate of hMSH2 methylation $(\mathrm{P}<0.001)$ and hMSH2 methylation was associated with IPSS-R

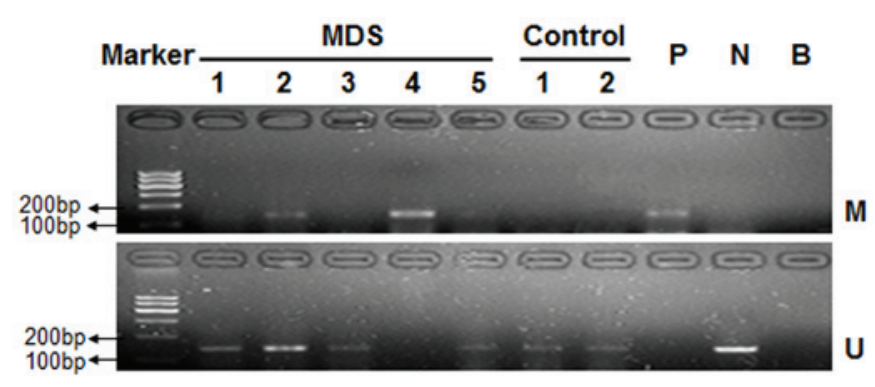

Figure 1. Methylation-specific PCR analysis of the hMSH2 promoter. M,PCR product amplified by methylated-specific primers; U, PCR product amplified by non-methylated-specific primers; $1-5$, the amplification products of the MDS patients group; 6-7, the amplification products of the control group; $\mathrm{P}$, positive control; $\mathrm{N}$, normal control; $\mathrm{B}$, blank control; $\mathrm{PCR}$, polymerase chain reaction; hMSH2, human mutS homolog 2; MDS, myelodysplastic syndromes.

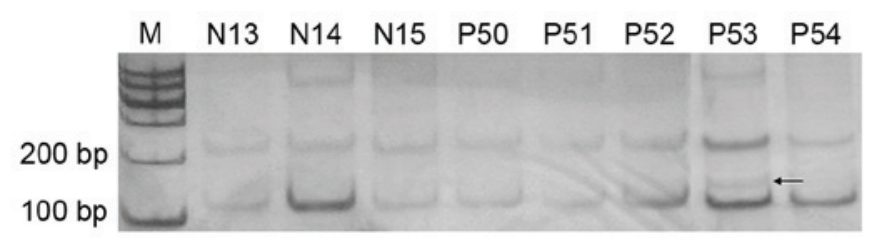

Figure 2. Microsatellite instability analysis of the BAT-26 locus. The arrow indicates the unstable locus. $\mathrm{M}$, molecular weight marker; $\mathrm{N}$, normal control; $\mathrm{P}$, patients with MDS.

based cytogenetic abnormalities in MDS $(\mathrm{P}=0.002)$ (both Table I). However, hMSH2 methylation was not observed to be associated with age, sex or peripheral blood parameters (neutrophils, hemoglobin or platelets).

MSI in MDS. To assess whether hMSH2 methylation was able to affect function of hMSH2 and the phenotype of cells, MSI testing of BAT-26 was performed in patients with MDS and controls (Fig. 2). None of the 15 controls exhibited MSI. Two of 60 patients exhibited MSI, who both also exhibited methylation of the hMSH2 promoter. Both patients with MSI were patients with RAEB-1. One patient exhibited 7- and 5q-karyotypic abnormalities and the other had a normal karyotype.

Expression of hMSH2 mRNA in MDS. RT-qPCR results revealed that patients with MDS had decreased hMSH2 mRNA expression compared with controls (median, 0.206 vs. 0.432 , $\mathrm{P}=0.005$; Fig. 3A) and hMSH 2 mRNA expression in MDS with hMSH2 methylation was significantly lower compared with non-methylation (median 0.166 vs. $0.246, \mathrm{P}=0.002$; Fig. $3 \mathrm{~A}$ ). hMSH2 expression was also compared between different IPSS-R risk groups. It was identified that hMSH2 mRNA expression was significantly decreased in patients with a high or very high IPSS-R risk compared with intermediate risk $(\mathrm{P}=0.003)$, and in patients with intermediate risk compared with low or very low risk $(\mathrm{P}=0.021$; Fig. $3 \mathrm{~B})$. To study the expression of hMSH2 in stem cells and mature cells of bone marrow, CD34+ and CD34-cells were isolated. Due to the limited number of bone marrow specimens, only 10 patients with MDS were included. It was identified that hMSH2 mRNA expression in CD34+ bone marrow cells was significantly 
Table I. hMSH2 methylation and clinical characteristics of patients with MDS.

\begin{tabular}{|c|c|c|c|c|}
\hline Characteristic & All & hMSH2 methylation & hMSH2 non-methylation & P-value \\
\hline \multicolumn{5}{|l|}{ Demographics } \\
\hline $\mathrm{n}(\%)$ & $60(100)$ & $18(30)$ & $42(70)$ & \\
\hline Median age, years (range) & $58.5(23-80)$ & $62(38-74)$ & $57(23-80)$ & 0.470 \\
\hline Sex, M/F (ratio) & $36 / 24(1.5: 1)$ & $9 / 9(1: 1)$ & 27/15 (1.8:1) & 0.300 \\
\hline WHO classification, n (\%) & & & & 0.017 \\
\hline RA & $9(15.0)$ & $1(11.1)$ & $8(88.9)$ & \\
\hline RARS & $2(3.3)$ & $0(0.0)$ & $2(100.0)$ & \\
\hline RCMD & $18(30.0)$ & $2(11.1)$ & $16(88.9)$ & \\
\hline MDS-U & $6(10.0)$ & $1(16.7)$ & $5(83.3)$ & \\
\hline RAEB-1 & $9(15.0)$ & $6(66.7)$ & $3(33.3)$ & \\
\hline RAEB-2 & $12(20.0)$ & $6(50.0)$ & $6(50.0)$ & \\
\hline AML-MRC & $4(6.7)$ & $2(50.0)$ & $2(50.0)$ & \\
\hline IPSS-R, n (\%) & & & & 0.001 \\
\hline Very low & $1(1.7)$ & $0(0.0)$ & $1(100.0)$ & \\
\hline Low & $15(25.0)$ & $2(13.3)$ & $13(86.7)$ & \\
\hline Intermediate & $21(35.0)$ & $2(9.5)$ & $19(90.5)$ & \\
\hline High & $16(26.7)$ & $10(62.5)$ & $6(37.5)$ & \\
\hline Very high & 7 (11.6) & $4(57.1)$ & $3(42.9)$ & \\
\hline \multicolumn{5}{|c|}{ Peripheral blood, median (IQR) } \\
\hline Neutrophils, x109/1 & $0.93(0.59-1.75)$ & $0.89(0.57-1.70)$ & $0.94(0.60-1.77)$ & 0.860 \\
\hline Hemoglobin, g/l & $67(55.00-79.25)$ & $67(61.00-77.75)$ & $67.5(52.75-79.75)$ & 0.540 \\
\hline Platelets, x $10^{9} / 1$ & $57.5(25.00-99.25)$ & $70(33.75-95.75)$ & $52(21.00-99.75)$ & 0.390 \\
\hline BM & & & & $4.04 \times 10^{-4}$ \\
\hline BM blast $\geq 5, \mathrm{n}(\%)$ & $25(41.7)$ & $14(56.0)$ & $11(44.0)$ & \\
\hline BM blast <5, n $(\%)$ & $35(58.3)$ & $4(11.4)$ & $31(88.6)$ & \\
\hline Cytogenetics, n (\%) & & & & 0.002 \\
\hline Very good & $2(3.3)$ & $1(50.0)$ & $1(50.0)$ & \\
\hline Good & $49(81.7)$ & $12(24.5)$ & $37(75.5)$ & \\
\hline Intermediate & $4(6.7)$ & $0(0.0)$ & $4(100.0)$ & \\
\hline Poor & $4(6.7)$ & $4(100.0)$ & $0(0.0)$ & \\
\hline Very poor & $1(1.6)$ & $1(100.0)$ & $0(0.0)$ & \\
\hline
\end{tabular}

MDS, myelodysplastic syndromes; hMSH2, human mutS homolog 2; M, male; F, female; WHO, World Health Organization; RA, refractory anemia; RARS, RA with ringed sideroblasts; RCMD, RA with multilineage dysplasia; MDS-U, unclassifiable MDS; RAEB-1, RA with excess blasts ( $<10 \%$ blasts); RAEB-2, RAEB ( $\geq 10 \%$ blasts); AML-MRC, acute myeloid leukemia with myelodysplasia-related changes; IPSS-R, Revised International Prognostic Scoring System; IQR, interquartile range (25-75\%); BM, bone marrow.

lower compared with CD34-bone marrow cells of patients with MDS ( $\mathrm{P}=0.029$; Fig. 3C).

Survival analysis. At a minimum follow-up of two years, 8 of 18 patients with hMSH2 methylation had succumbed to mortality and the median survival period was 19 months; whereas in the non-methylated group, 4/42 patients had succumbed to mortality and the median survival period was $>2$ years. The Kaplan-Meier curve indicated that overall survival (OS) was significantly decreased in patients with hMSH2 methylation: The two-year OS was $42 \%$ (95\% CI, 14.2-69.8\%) in methylated patients compared with $68.2 \%$ (95\% CI, 38-98.4\%) in non-methylated patients ( $\mathrm{P}=0.011$; Fig. 4).

\section{Discussion}

MMR gene abnormalities disrupt the repair of base mismatches in DNA replication, resulting in genome instability and tumor susceptibility (20). In the present study, methylation of hMSH2 was observed in 18 out of 60 patients with MDS using methylation-specific PCR. According to IPSS-R grouping, methylation of hMSH2 was more common in higher risk MDS. hMSH2 methylation was associated with IPSS-R based cytogenetic abnormalities in MDS. These data suggest a possible role of hMSH2 promoter methylation in the progress of MDS. Sheikhha et al (21) previously used a PCR-based restriction enzyme assay to detect hMSH2 methylation status in 68 patients with AML and 14 patients with MDS, and 
A

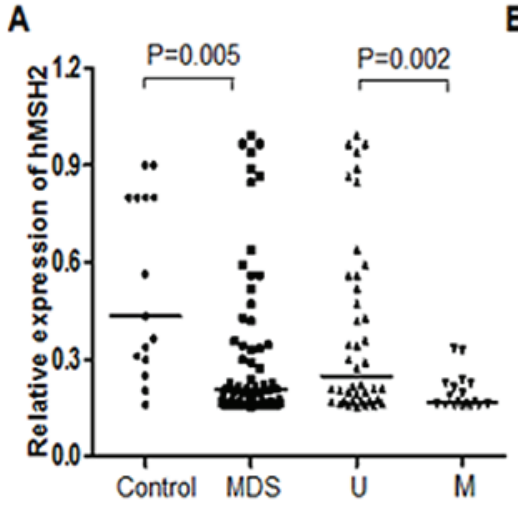

B

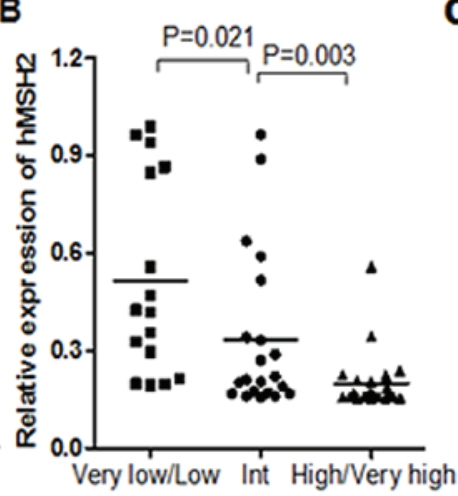

C

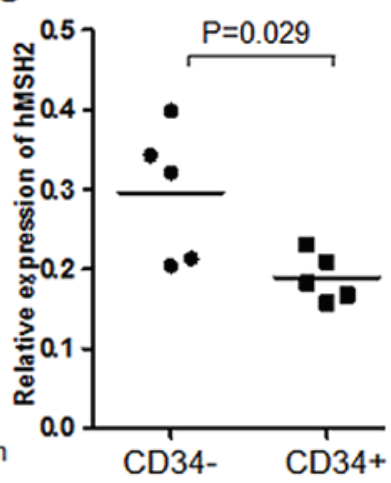

Figure 3. Analysis of hMSH2 mRNA expression in patients with MDS. (A) Differential expression of hMSH2 in patients with MDS, who were also with or without hMSH2 methylation. (B) hMSH2 mRNA expression in different Revised International Prognostic Scoring System risk groups. (C) Differential expression of hMSH2 in CD34+ and CD34- cells. MDS, myelodysplastic syndromes; hMSH2, human mutS homolog 2; Int, intermediate; M, hMSH2 methylation; $\mathrm{U}, \mathrm{hMSH} 2$ non-methylation; CD, cluster of differentiation; CD34-, CD34 negative; CD34+, CD34 positive.

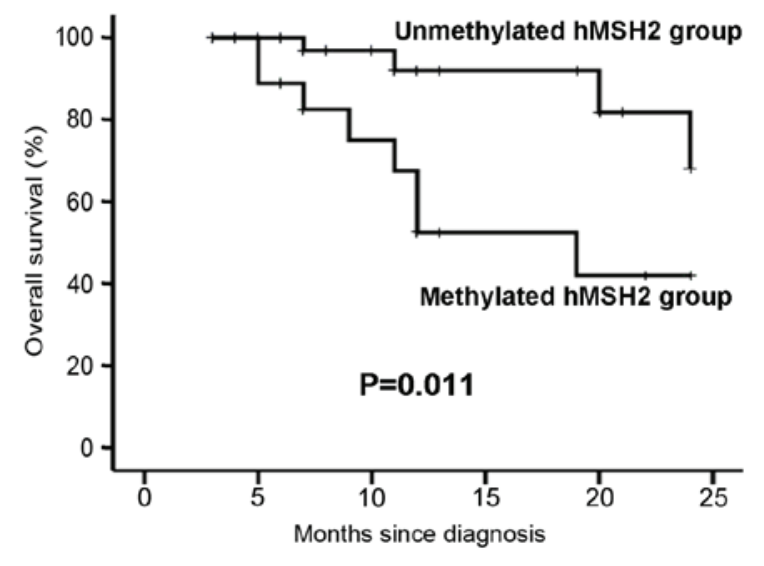

Figure 4. Kaplan-Meier curves for overall survival in patients with myelodysplastic syndrome who also possessed hMSH2 methylation and non-methylation. Log-rank test, $\mathrm{P}=0.011$. hMSH2, human mutS homolog 2.

identified 5 cases of methylation, all in patients with AML ( 2 secondary AML, 1 therapy-related AML), which suggested that hMSH2 methylation may have a role in the development of AML. However, in a different study, a high rate of MMR gene promoter methylation was identified in therapy-related leukemia and MDS (62.5\% for hMSH2) (22). Contradictory results may arise from patient selection bias, sample size and methods used. Therefore, further investigation into the role of MMR methylation in myeloid neoplasms is required.

MSI is associated with MMR dysfunction. A previous report suggested MSI of marker BAT-26 was a reliable indicator of a replication error phenotype (18). The germline polymorphisms of BAT-26 in Chinese individuals are quasimonomorphic, and no matched genomic DNA is needed when BAT-26 is selected for tumor MSI analysis (23). Therefore, BAT-26 was used to detect the impact of hMSH2 methylation upon hMSH2 function. In the present study, 2 patients with hMSH2 methylation exhibited alterations of marker BAT-26. In addition to being a key component of MMR, the human MMR genes are also associated with apoptosis and cell cycle regulation $(24,25)$. The current results suggested that hMSH2 gene methylation affected its MMR function, but it may also play a role in cell cycle regulation and apoptosis.
Aberrant hMSH2 expression in patients with AML has been described previously (26). One previous study detected hMSH2 protein expression in 10 normal individuals and 9 patients with MDS, and found it was predominantly expressed in myeloblasts and promyelocytes (27). Blast cells from late stage MDS (RAEB/RAEB-T) exhibited absent or very low hMSH2 expression (28). Using RT-qPCR, it was demonstrated in the current study that MDS patients had lower hMSH2 expression compared with controls, and CD34+ cells from MDS bone marrow had lower hMSH2 expression compared with CD34-cells, suggesting that hMSH2 may affect differentiation of hematopoietic cells.

It is worth noting that patients in the very low/low risk groups had a lower hMSH2 methylation rate compared with the intermediate and high/very high risk groups, and hMSH2 promoter methylation was associated with shorter OS in patients with MDS, suggesting hMSH2 promoter methylation may be used as a prognostic indicator for patients with MDS.

In conclusion, it was demonstrated in the current study that the incidence of hMSH2 methylation is $\sim 30 \%$ in patients with MDS. Among patients with hMSH2 methylation, 2 patients displayed MSI of marker BAT-26. It was identified that hMSH2 promoter methylation was increased in MDS with higher IPSS-R risk, and hMSH2 methylation was associated with cytogenetic abnormalities of MDS. Patients with MDS with higher hMSH2 promoter methylation also had shorter OS, suggesting hMSH2 promoter methylation may be valuable for prognostic evaluation and progression prediction of MDS. In addition, it was also observed that decreased hMSH2 mRNA expression was associated with the high IPSS-R risk group. Aberrant gene methylation not only correlates with tumor suppressor gene silence in the process of MDS pathogenesis and progress to AML, but is also associated with the prognosis of patients with MDS (29). Molecular studies of epigenetic alterations will contribute to the development of targeted therapies for patients with MDS.

\section{Acknowledgments}

The present study was supported in part by the Scientific Research Program for Public Interests from the Health 
Ministry of China (grant no. 201202017) and the National Natural Science Fund of China (grant no. 81500141).

\section{References}

1. Tefferi A and Vardiman JW: Myelodysplastic syndromes. N Engl J Med 361: 1872-1885, 2009.

2. Vardiman JW, Thiele J, Arber DA, Brunning RD, Borowitz MJ, Porwit A, Harris NL, Le Beau MM, Hellström-Lindberg E, Tefferi A and Bloomfield CD: The 2008 revision of the World Health Organization (WHO) classification of myeloid neoplasms and acute leukemia: Rationale and important changes. Blood 114 937-951, 2009

3. Nolte F and Hofmann WK: Myelodysplastic syndromes: Molecular pathogenesis and genomic changes. Ann Hematol 87: 777-795, 2008.

4. Esteller M: Epigenetics in cancer. N Engl J Med 358: 1148-1159, 2008.

5. Aggerholm A, Holm MS, Guldberg P, Olesen LH and Hokland P: Promoter hypermethylation of p15INK4B, HIC1, CDH1, and ER is frequent in myelodysplastic syndrome and predicts poor prognosis in early-stage patients. Eur J Haematol 76: 23-32, 2006

6. Figueroa ME, Skrabanek L, Li Y, Jiemjit A, Fandy TE, Paietta E, Fernandez H, Tallman MS, Greally JM, Carraway H, et al: MDS and secondary AML display unique patterns and abundance of aberrant DNA methylation. Blood 114: 3448-3458, 2009.

7. Silverman LR, Demakos EP, Peterson BL, Kornblith AB Holland JC, Odchimar-Reissig R, Stone RM, Nelson D, Powell BL, DeCastro CM, et al: Randomized controlled trial of azacitidine in patients with the myelodysplastic syndrome: A study of the cancer and leukemia group B. J Clin Oncol 20 : 2429-2440, 2002.

8. Yu Z, Chen J, Ford BN, Brackley ME and Glickman BW: Human DNA repair systems: An overview. Environ Mol Mutagen 33: 3-20, 1999.

9. Bellacosa A: Functional interactions and signaling properties of mammalian DNA mismatch repair proteins. Cell Death and Differentiation 8: 1076-1092, 2001.

10. Fishel R, Lescoe MK, Rao MR, Copeland NG, Jenkins NA, Garber J, Kane M and Kolodner R: The human mutator gene homolog MSH2 and its association with hereditary nonpolyposis colon cancer. Cell 75: 1027-1038, 1993.

11. Peltomäki P: DNA mismatch repair and cancer. Mutat Res 488 $77-85,2001$.

12. Greenberg PL, Tuechler H, Schanz J, Sanz G, Garcia-Manero G, Solé F, Bennett JM, Bowen D, Fenaux P, Dreyfus F, et al: Revised international prognostic scoring system for myelodysplastic Syndromes. Blood 120: 2454-2465, 2012.

13. Czepulkowski B, Bhatt B, et al (eds): Basic techniques for the preparation and analysis of chromosomes from bone marrow and leukaemic blood. Human cytogenetics: Malignancy and acquired abnormalities, 3rd edition. Oxford, Oxford University Press, pp1-26, 2001.

14. Simons A, Shaffer LG and Hastings RJ: Cytogenetic Nomenclature: Changes in the ISCN 2013 compared to the 2009 edition. Cytogenet Genome Res 141: 1-6, 2013.
15. Crescenzi B, La Starza R, Romoli S, Beacci D, Matteucci C, Barba G, Aventin A, Marynen P, Ciolli S, Nozzoli C, et al: Submicroscopic deletions in 5q-associated malignancies. Haematologica 89: 281-285, 2004.

16. Herman JG, Graff JR, Myöhänen S, Nelkin BD and Baylin SB: Methylation-specific PCR: A novel PCR assay for methylation status of CpG islands. Proc Natl Acad Sci USA 93: 9821-9826, 1996.

17. Herman JG, Umar A, Polyak K, Graff JR, Ahuja N, Issa JP, Markowitz S, Willson JK, Hamilton SR, Kinzler KW, et al: Incidence and functional consequences of hMLH1 promoter hypermethylation in colorectal carcinoma. Proc Natl Acad Sci USA 95: 6870-6875, 1998.

18. Hoang JM, Cottu PH, Thuille B, Salmon RJ, Thomas G and Hamelin R: BAT-26, an indicator of the replication error phenotype in colorectal cancers and cell lines. Cancer Res 57: 300-303, 1997.

19. Xu L, Liu C, Chang Y, Liang L, Liu J, Gao G and Han Q: Theory and method of double-standard curves method of relative quantification PCR. Biotechnol Bulletin 1: 70-75, 2011.

20. Boland CR and Goel A: The silence of the genes: Matching mismatch repair defects with tumors. Cancer 98: 2091-2094, 2003.

21. Sheikhha MH, Tobal K and Liu Yin JA: High level of microsatellite instability but not hypermethylation of mismatch repair genes in therapy-related and secondary acute myeloid leukaemia and myelodysplastic syndrome. Br J Haematol 117: 359-365, 2002.

22. Krichevsky S, Siegfried F, Asimakopoulos FA, Shteper PJ, Goldschmidt N, Rachmilewitz EA, Rund D and Ben-Yehuda D: Methylation of the promoter regions of DNA repair and genotoxic stress response genes in therapy-related but not primary leukemia. Blood 94: 594a, 1999.

23. Lu BJ, Lai MD, Huang Q and Sheng HQ: Germline polymorphisms of Bat26 and its significance in gastric cancer microsatellite instability. Zhejiang Da Xue Xue Bao Yi Xue Ban 34: 353-357, 2005 (In Chinese).

24. Carethers JM, Hawn MI, Chauhan DP, Luce MC, Mama G, Koi $\mathrm{M}$ and Boland CR: Competency in mismatch repair prohibits clonal expansion of cancer cells treated with $\mathrm{N}$-methyl-N'-nitro-N-nitrosoguanidine. J Clin Invest 98: 199-206, 1996.

25. Zhang H, Richards B, Wilson T, Lloyd M, Cranston A, Thorburn A, Fishel R and Meuth M: Apoptosis induced by overexpression of hMSH2 or hMLH1. Cancer Res 59: 3021-3027, 1999.

26. Zhu YM, Das-Gupta EP and Russell NH: Microsatellite instability and p53 mutations are associated with abnormal expression of the MSH2 gene in adult acute leukemia. Blood 94: 733-740, 1999.

27. Austin HS: Etica y psiconanálisis. Br J Haematol 111: 650-655, 2004.

28. Maeck L, Kohaus P, Haase D, Hiddemann W and Alves F. Differential cellular expression of the human MSH2 protein in normal and myelodysplastic haematopoiesis. Br J Haematol 111: $650-655,2000$

29. Shen L, Kantarjian H, Guo Y, Lin E, Shan J, Huang X, Berry D, Ahmed S, Zhu W, Pierce S, et al: DNA methylation predicts survival and response to therapy in patients with myelodysplastic syndromes. J Clin Oncol 28: 605-613, 2010. 